\title{
МЕТОДИЧЕСКИЕ АСПЕКТЫ УЧЕТА МЕЖПРЕДМЕТНЫХ СВЯЗЕЙ В ОБРАЗОВАТЕЛЬНОМ ПРОЦЕССЕ
}

\section{Решетникова И.С.}

ИПТиБ (филиал) ФГБОУ ВО «МГУТУ им. К.Г. Разумовского (ПКУ)», г. Смоленск, Российская Федерация

В статье дан анализ понятия «межпредметные связи» выделены типы межпредметных связей установлены способы принципы и уровни реализации межпредметных связей при организации учебного прочесса в профессиональном обучении.

Ключевые слова: межпредметные связи; организация учебного прочесса профессиональное образование.

\section{METHODOLOGICAL ASPECTS OF INTERDISCIPLINARY COMMUNICATION IN THE EDUCATIONAL PROCESS}

\section{Reshetnikova I.S.}

Institute of Food Technologies and Business (branch) of Moscow State University of Technology and Management named after K.G. Razumovsky (First Cossack University), Smolensk,

Russian Federation

The article analyzes the concept of "intersubject communication", identifies the types of intersubject communication, established methods, principles and levels of implementation of intersubject communication in the organization of the educational process in vocational training.

Keywords: intersubject communications; organization of educational process; professional education. 
Для того чтобы общеобразовательные предметы приблизить к целям и задачам учебного заведения они должны носить профессиональную направленностью. Определяет профессиональную направленность общеобразовательных дисциплин содержание профессиональной образовательной программы. Выделение в курсах общеобразовательных предметов материала применяющегося на специальных дисциплинах насыщение занятий задачами, примерами проблемными вопросами и ситуациями профессионального характера способствует воспитанию ценностного отношения к своей профессии.

На сегодняшний день перед преподавателем стоит задача соединения знаний в единую систему общего и профессионального образования. Систематическая акцентуализация межпредметных связей содействует формированию умения комплексного применения знаний различных предметов в процессе профессионального обучения.

Обучающиеся за короткий семестровый период получают большой объём знаний и информаций по ранее незнакомым спецдисциплинам. При этом им необходимо сконцентрировать и объединить разнообразные знания, умения навыки теоретического лабораторного и практического курса. Всё это обучающимися должно восприниматься как единый взаимосвязанный комплекс. Обучаемый должен соотносить знания, полученные в аудитории по различным спецдисциплинам, и устанавливать межпредметные связи между ними что самостоятельно обучающемуся сделать достаточно трудно.

Межпредметные связи в системе профессионального образования приобретают особое значение, учебный и познавательный процесс должен строиться в органической связи с общеобразовательными общепрофессиональными и специальными дисциплинами.

\section{Понятие «межпредметные связи»}

Понятие «межпредметные связи» относится к общедидактическим понятиям:

- межпредметные связи это отражение межнаучных связей в учебном процессе (на уровне дидактического явления; 
- межпредметные связи это фактор взаимодействия наук в процессе формирования диалектического мировоззрения обучающихся (на уровне дидактического процесса.

- межпредметные связи определяют целевую направленность на формирование в сознании человека целостной системы знаний на уровне дидактического принципа).

- межпредметные знания это самостоятельная область дидактических знаний, имеющая психолого-педагогическое обоснование и характеризующаяся целостной структурой принципов методов и средств обучения (на уровне методологии).

Можно выделить три модели межпредметных связей:

1) общеобразовательные дисциплины - спецдисциплины;

2) общепрофессиональные дисциплины - спецдисциплины;

3) спецдисциплины - спецдисциплины.

При установлении и реализации межпредметных связей необходимо:

1. Исходя из темы четко формулировать учебно-познавательную цель и образовательные развивающие и воспитательные задачи направленные на усвоение ведущих положений и основных знаний изучаемой темы;

2. Обеспечивать активность обучающихся по применению знаний из других дисциплин;

3. Объяснять причинно-следственные связи сущности изучаемых явлений и процессов;

4. Содержать выводы мировоззренческого обобщенного характера опирающиеся на связь знаний из разных дисциплин;

5. Нацеливать на обобщение определенных разделов учебного материала изучаемого в разных дисциплинах.

Существуют следующие типы междисциплинарных связей:

1. Учебно-междисциплинарные прямые связи. Они возникают в случае если усвоение одной дисциплины базируется на знании другой. При изучении определяется базисное ядро знаний по каждой дисциплине, ее тезаурус, структура связей дисциплин.

2. Исследователъско-междисциплинарные связи проблемного характера. Возникают тогда когда две (или более дисциплины имеют 
общий объект исследования или общие проблемы но рассматриваются с разных дисциплинарных подходов в различных аспектах.

3. Ментально-опосредованные связи, которые возникают в том случае когда средствами разных учебных дисциплин формируются одни и те же компоненты, интеллектуальные умения, необходимые в профессиональной деятельности. Ментально-опосредованные связи возникают при изучении общеинженерных и профессиональных дисциплин. Они касаются процессуальной стороны преподавания, развивают профессионально-интеллектуальные умения.

4. Опосредованно-прикладные связи, которые формируются тогда, когда понятия одной науки используются при изучении другой.

Межпредметные связи осуществляются преподавателями: на отдельных занятиях эпизодические - первый уровень; в системе занятий (частно-системные) - второй уровень; постоянно системные - третий уровень. Третий уровень наиболее оптимален и эффективен так как очень важно чтобы обучающиеся видели в работе преподавателя и в его деятельности определенную систему.

Программа - основной документ, по которому организуется весь учебный процесс на занятии. Она раскрывает цели и задачи изучения дисциплины логику ее построения, регулирует преемственность отдельных ее частей указывает на тесную взаимосвязь с другими дисциплинами. В содержание программы любой дисциплины входят: опыт осуществления известных способов деятельности воплощающихся вместе со знаниями в навыки и умения личности; опыт профессиональной деятельности; опыт эмоционально-ценностных отношений к знаниям и действительности. Все перечисленные элементы содержания образования присутствуют в дисциплинах теоретического и профессиональных циклов. Каждый из них выполняет свою функцию в подготовке специалиста.

Преподаватель должен обеспечить обучение различным видам знаний в комплексе. Очень важно ознакомить обучающихся со знаниями о способах такой деятельности, как: анализ и проектирование технологических процессов; разбор и составление схем, выполнение расчетов, решение профессиональных задач работа с литературой и 
нормативной документацией. Специфика профессиональных дисциплин заключается в наличии тесной связи с профессиональным обучением, а это значит что полученные теоретические знания должны быть интегрированы в практическую деятельность обучающихся. Навыки и умения появляются у обучающихся только тогда, когда они делают опыт, накопленный человечеством, своим в процессе собственной деятельности.

\section{Уровни организации учебного процесса \\ на основе междисциплинарных связей}

Выделяются следующие уровни организации учебного процесса на основе междисциплинарных связей:

- тематический - вся система занятий учебной темы подчиняется решению крупной междисциплинарной проблемы;

- сквозной - система занятий охватывающих несколько учебных тем разных курсов;

- внутрицикловой например одна и та же тема в разных дисциплинах;

- межцикловой разные дисциплины - общие темы - дополняют друг друга конкретизация учебного материала в ракурсе межпредметной системы.

Результативность обучения при учете междисциплинарных связей выявляется на основании:

- умений обучающихся осуществлять междисциплинарный перенос знаний при решении познавательных и профессиональных задач, самостоятельно решать крупные междисциплинарные проблемы (увидеть проблему составить план ее решения отобрать нужные знания из разных предметов обобщить их сделать выводы;

- мотивации учебно-познавательной деятельности обучающихся на основе междисциплинарных связей;

- степени трудности междисциплинарных заданий для обучающихся разных курсов и разной подготовки к установлению связей. 
Выявление и последующее осуществление межпредметных связей позволяет доводить приобретенные знания до практического воплощения, сосредоточив внимание преподавателей и обучающихся на узловых аспектах учебных дисциплин, а так же осуществлять поэтапную организацию работы по установлению межпредметных связей постоянно усложняя познавательные задачи расширяя поле действия творческой инициативы и познавательной деятельности, применяя все многообразие дидактических средств для эффективного осуществления многосторонних межпредметных связей;

Акцент на межпредметные связи формирует познавательные интересы обучающихся средствами самых различных учебных дисциплин в их органическом единстве, позволяет осуществлять творческое сотрудничество между преподавателями и обучающимися устраняет дублирование при изучении одних и тех же вопросов на уроках смежных дисциплин.

\section{Планирование межпредметных связей}

Содержание и основные направления осуществления межпредметных связей представимы в виде следующей системы:

1. Средства, при помощи которых осуществляются межпредметные связи: сетевое планирование учебного процесса; перспективно-тематическое планирование; составление графиков взаимосвязи учебных дисциплин профессионального обучения; группировка дисциплин в циклах.

2. Основные направления в осуществлении межпредметных связей: разработка карточек - заданий; изготовление наглядных пособий по межпредметным связям; разработка комплексных заданий для прохождения профессионального обучения и практики.

3. Пути и формы осуществления межпредметных связей: различные типы занятий; научные кружки; комплексные экскурсии; конференции проводимые по новым технологиям а также групповые собрания по итогам производственной практики.

Применение межпредметных связей между специальными, общеобразовательными дисциплинами и профессиональным обучением способствует подготовке высококвалифицированных специалистов. 
Способом достижения на практике желаемого результата при использовании межпредметных связей является видовое многообразие учебных занятий. Виды занятий с целью использования межпредметных связей различаются следующие:

1) бинарное занятие - учебное занятие, объединяющее содержание двух предметов одного цикла или образовательной области в одном. Особенностью такого занятия является то, что изложение, исследование проблемы одного предмета находит продолжение в другом. При бинарном занятии межпредметные связи реализуются в процессе преподавания дисциплин одной образовательной области. При проведении бинарного занятия одна и та же тема рассматривается сразу двумя дисциплинами любого блока.

2) интегрированное занятие - учебное занятие на котором обозначенная тема рассматривается с различных точек зрения, средствами нескольких предметов (курсов). Ведут его два или даже несколько преподавателей. При проведении интегрированного занятия тема по одной дисциплине дополняется знаниями из другой дисциплины, но по теме, которая, опираясь на предыдущие знания, дает более широкое познавательное формирование.

3) межпредметное занятие - эта форма занятий, при которой изучаемый учебный материал иллюстрируется сведениями из других дисциплин, обеспечивая при этом синхронность обучения по пересекающимся темам нескольких дисциплин, которые разделены по времени (семестры, курсы).

4) производственная практика. Производственное обучение, когда теория и профессиональная практика ведутся в параллели в полной мере реализует межпредметные связи.

Межпредметные связи позволяют: развивать у обучающихся навыки использования знаний общеобразовательных и общепрофессиональных дисциплин для усвоения и понимания спецдисциплин; оптимизировать учебный процесс, используя элементы современных педагогических и информационных технологий; преподносить учебный материал, активизируя мыслительные способности обучаемых с использованием потенциала их знаний; создавать возможности для 
интеграции наук, необходимых в будущей деятельности специалистов в производстве и научной сфере. Использование межпредметных связей в процессе подготовки к занятиям требует значительного количества времени и взаимодействия всех преподавателей.

Анализируя проблему межпредметных связей, можно сказать, что вся работа преподавателей по реализации межпредметных связей должна быть направлена на создание у обучающихся продуктивной, единой по содержанию и структуре системы знаний, умений, навыков - системы, которая помогала бы им использовать всю сумму накопленных ими знаний при изучении любого теоретического или практического вопроса.

\section{Список литературы}

1. Мартынова Е.В., Решетникова И.С., Смирнов В.В., Купцова В.В., Пронина О.В., Титов Ю.М., Кондратьева Э.В. Использование современных педагогических технологий для формирования мотивации студентов к самосовершенствованию // Наука и образование в социокультурном пространстве современного общества, Сб. науч. трудов по материалам Междунар. научно-практ. конф. В 3-х частях. 2016. C. 82-83.

2. Решетникова И.С. Математическая модель адаптации студентов к использованию информационных технологий в образовании. Чебоксары: ЦНС «Интерактивплюс», 2014.

3. Решетникова И.С. Структурные элементы и методика проведения компьютерного занятия при изучении пакетов математических программ // Академические Жуковские чтения. Актуальные проблемы математических и естественнонаучных дисциплин при подготовке военных специалистов: сб. науч. ст. по материалам Всероссийской ПНК (20-21 ноября 2013 года): в 2-х ч. Воронеж: ВУНЦ ВВС «ВВА», 2014. Ч. 2. 160 c. С. 92-94.

\section{References}

1. Martynova E.V., Reshetnikova I.S., Smirnov V.V., Kuptsova V.V., Pronina O.V., Titov Yu.M., Kondrat'eva E.V. Ispol'zovanie sovremennykh 
pedagogicheskikh tekhnologiy dlya formirovaniya motivatsii studentov k samosovershenstvovaniyu // Nauka i obrazovanie v sotsiokul'turnom prostranstve sovremennogo obshchestva, $\mathrm{Sb}$. nauch. trudov po materialam Mezhdunar. nauchno-prakt. konf. V 3-kh chastyakh. 2016. S. 82-83.

2. Reshetnikova I.S. Matematicheskaya model' adaptatsii studentov k ispol'zovaniyu informatsionnykh tekhnologiy v obrazovanii. Cheboksary: TsNS «Interaktivplyus», 2014.

3. Reshetnikova I.S. Strukturnye elementy i metodika provedeniya komp'yuternogo zanyatiya pri izuchenii paketov matematicheskikh programm // Akademicheskie Zhukovskie chteniya. Aktual'nye problemy matematicheskikh i estestvennonauchnykh distsiplin pri podgotovke voennykh spetsialistov: sb. nauch. st. po materialam Vserossiyskoy PNK (20-21 noyabrya 2013 goda): v 2-kh ch. Voronezh: VUNTs VVS «VVA», 2014. Ch. 2. 160 s. S. 92-94. 